\title{
Reply to Davis and Hart: Unlikely confidence in the size of a sample
}

GORDON F. PITZ, DEPARTMENT OF PSYCHOLOGY, SOUTHERN ILLINOIS UNIVERSITY, Carbondale, Ill. 62901

The comments made by Davis \& Hart (1968) concerning a study by Pitz (1967) appear to reflect a misunderstanding of the use of likelihoods in statistical decision theory. (See Chernoff \& Moses, 1959, Chap. 9.) A likelihood is the joint probability of a sequence of observations, $X_{1}, X_{2}, \ldots, X_{n}$, conditional upon some population parameter, $\pi$. For the case in question, a sequence of red and blue balls is generated according to a Bernoulli process, where the probability of a red ball is $\pi$. In a sequence of $\mathrm{N}$ events, let there be $\mathrm{R}$ red balls and $\mathrm{B}$ blue balls; the likelihood of this sequence is

$$
\operatorname{Pr}\left(X_{1}, X_{2}, \ldots, X_{n} \mid \pi\right)=\pi^{R}(1-\pi)^{B} \text {. }
$$

If $\pi$ is completely unknown, a widely used method for estimation is to take the value of $\pi$ that maximizes the likelihood defined above. This maximum likelihood estimate is

$$
\mathrm{P}=\mathrm{R} /(\mathrm{R}+\mathrm{B})=\mathrm{R} / \mathrm{N} \text {, }
$$

and its precision is a function of $\mathrm{N}$. However, in the original study by Pitz (1967), Ss knew that $\pi$ was either 0.6 or 0.4 . In this event, the estimate $\mathrm{P}$ is irrelevant. Instead, a decision concerning $\pi$ should be made on the basis of the likelihood ratio, i.e., the ratio of the two relevant likelihoods. Thus,

$$
\frac{\operatorname{Pr}\left(X_{1}, X_{2}, \ldots, X_{n} \mid \pi=0.6\right)}{\operatorname{Pr}\left(X_{1}, X_{2}, \ldots, X_{n} \mid \pi=0.4\right)}=\left(\frac{0.6}{0.4}\right)^{R}\left(\frac{0.4}{0.6}\right)^{B}=\left(\frac{0.6}{0.4}\right)^{R-B}
$$

The importance of the likelihood ratio is that it summarizes all of the relevant information in a sequence, and may be thought of as the diagnostic impact of that sequence. Thus, for this particular problem, only the difference $\mathbf{R}-\mathbf{B}$ is relevant to a decision.

If one adopts a Bayesian point of view (Edwards, Lindman, \& Savage, 1963; Pitz, in press), one may convert a likelihood ratio into a posterior probability. This conversion is not essential to the conclusions of the original study, but it helps to make the point clear. When the two values of $\pi$ are initially equally likely, we have

$$
\operatorname{Pr}\left(\pi=0.6 \mid X_{1}, X_{2}, \ldots, X_{n}\right)=\frac{\left(\frac{0.6}{0.4}\right)^{R-B}}{1+\left(\frac{0.6}{0.4}\right)^{R-B}}
$$

Optimally, then, one's confidence in a decision should be a function of $\mathrm{R}$ - B only, not of $\mathrm{N}$ or $\mathrm{P}$, except insofar as they are related to the difference. If a $S$ 's confidence varies as a function of $\mathbf{N}$ for a constant $\mathbf{R}$ - $\mathbf{B}$, as happened, that $\mathbf{S}$ is being nonoptimal. On the other hand, confidence certainly did increase as the absolute difference increased, as it should. At no point in the original paper was the statement made that a person becomes less confident as he gathers more evidence. The point should be made, however, that no reasonable individual-S or statistician-should allow the sample size to affect his judgment independently of the likelihood ratio. Whether or not Ss do behave this way is another question.

\section{REFERENCES}

CHERNOFF, H., \& MOSES, L. E. Elementary decision theory. New York: Wiley, 1959.

DAVIS, D. J. \& HART, M. D. Sample size, confidence, and optimality: Reinterpretation of a previous study. Psychon. Sci, 1968,000000 000 .

EDWARDS, W., LINDMAN, H., \& SAVAGE, L. J. Bayesian statistical inference for psychological research. PsychoL Rev., 1963, 70, 193-242.

PITZ, G. F. Sample size, likelihood, and confidence in a decision. Psychon. Sci. 1967, 8, 257-258.

PITZ, G. F. An example of Bayesian hypothesis testing: The perception of rotary motion in depth. Psychol Bull., in press. 